\title{
APRENDIZAGEM E INTERAÇÃO NA REDE SOCIAL FACEBOOK
}

\author{
Geovanna Cristina Falcão Soares Rodrigues ${ }^{1}$ \\ Universidade Federal da Paraíba \\ geovannacristinaf@yahoo.com.br \\ Edna Gusmão de Góes Brennand ${ }^{2}$ \\ Universidade Federal da Paraíba \\ ednabrennand@gmail.com
}

\begin{abstract}
Resumo
Este artigo tem como objeto de estudo as interações que ocorrem nos sites de rede sociais, com o objetivo de analisar como as diferentes formas de interações ocorridas nos sites de redes sociais estão relacionadas a aprendizagens. Os dados foram coletados através da rede social Facebook a partir de postagens em seis páginas da referida rede social e analisados por meio das técnicas de análise de redes sociais e de análise de conteúdo, com auxílio de softwares. Os resultados encontrados apontaram que os sites de redes sociais, ao oferecer aos usuários diferentes possibilidades de interação e estimulam as redes de aprendizagens em suas dimensões cognitiva, afetiva e vivencial. As interações se relacionam a aprendizagens quando - através das postagens, compartilhamentos, comentários e reações - possibilitam que as pessoas dividam conhecimento, dialoguem, produzam conteúdo e expressem sentimentos e percepções, em uma rede infinita de possibilidades.
\end{abstract}

Palavras-chave: Cultura Digital. Redes sociais. Aprendizagem. Interação. Facebook.

\section{LEARNING AND INTERACTION IN THE FACEBOOK SOCIAL NETWORK}

\begin{abstract}
The purpose of this article is to study the interactions that occur on social networking sites, with the aim of analyzing how the different forms of interactions that occur on social networking sites are related to learning. The data were collected through the Facebook social network from posts on six pages of that social network and analyzed using social network analysis and content analysis techniques, with the aid of software. The results found pointed out that social networking sites, offering users different possibilities for interaction and stimulate learning networks in their cognitive, affective and experiential dimensions. Interactions are related to learning when through posts, shares, comments and reactions - they enable people to share knowledge, dialogue, produce content and express feelings and perceptions, in an infinite network of possibilities.
\end{abstract}

Keywords: Digital Culture. Social networks. Learning. Interaction. Facebook.

\footnotetext{
${ }^{1}$ Possui graduação em Pedagogia pela Universidade Federal da Paraíba (2008), graduação em Psicologia pela Universidade Federal da Paraíba (2018) e doutorado em Educação pela Universidade Federal da Paraíba (2019).

2 Professora Titular da Universidade Federal da Paraíba. Possui Pós-Doutorado pela Université Catholique de Louvain-UCL Bélgica (2005) e na Universidade Lusófona de Humanidades e Tecnologias- ULHT -Portugal (2012). Estágio Sênior em andamento na Universidad de València. Doutorado em Sociologia - Université Paris I Panthéon Sorbonne . Mestrado em Educação pela Universidade Federal da Paraíba.
}

(c) (1) Esta obra está licenciada sob uma licença BY NC SA Creative Commons Attribution 4.0 International (CC BY-NC-SA 4.0). P2P \& INOVAÇÃO, Rio de Janeiro, v. 7, n. 1, p. 88-106, set. 2020/fev. 2021. 


\section{APRENDIZAJE E INTERACCIÓN EN LA RED SOCIAL FACEBOOK}

\section{Resumen}

Este artículo tiene como objetivo estudiar las interacciones que ocurren en los sitios de redes sociales, con el objetivo de analizar cómo las diferentes formas de interacciones que ocurren en los sitios de redes sociales se relacionan con el aprendizaje. Los datos fueron recolectados a través de la red social Facebook a partir de publicaciones en seis páginas de esa red social y analizados utilizando técnicas de análisis de redes sociales y análisis de contenido, con la ayuda de software. Los resultados encontrados mostraron que los sitios de redes sociales, al ofrecer a los usuarios diferentes posibilidades de interacción y estimular las redes de aprendizaje en sus dimensiones cognitiva, afectiva y experiencial. Las interacciones están relacionadas con el aprendizaje cuando, a través de publicaciones, compartidos, comentarios y reacciones, permiten a las personas compartir conocimientos, dialogar, producir contenidos y expresar sentimientos y percepciones, en una red infinita de posibilidades.

Palavras-clave: Cultura digital. Redes sociales. Aprendizaje. Interacción. Facebook.

\section{INTRODUÇÃO}

A partir de meados do século XX a sociedade experimenta os avanços da tecnologia especialmente no que diz respeito às tecnologias digitais provenientes da Internet. A Internet enquanto meio de comunicação de liberdade para a liberdade gera um inovador espaço de interações e troca de informações entre as pessoas, que marca o início de novos tempos na estrutura das comunicações e relações humanas.

Em sua organização o ambiente virtual é constituído por redes e configurado pela atemporalidade e ausência de limites territoriais. É um espaço de fluxos, de circulação, personalização, descentralização de informações e permuta de conhecimentos (DYSSON, GILDER, KEYWORTH e TOFFLER, 1994). Local de infinitas interações que rodeia a todos e no qual as pessoas se inserem pelo uso da internet e demais tecnologias digitais.

Entre as mídias digitais com mais acesso na Internet estão os sites de redes sociais, que são ambientes computacionais criados para reunir e conectar pessoas. Esses espaços atraem a atenção dos usuários pela facilidade de acesso (login e senha) e navegação (interface), como também por reunir em um só lugar diferentes possibilidades interacionais com diversas pessoas e informações.

Conforme Recuero, Bastos e Zago (2015, p. 25) as redes sociais são "sites e tecnologias digitais, que permitem que duas ou mais pessoas se comuniquem livremente, sem intermediários, discutindo, conversando, e compartilhamento informações”. As pessoas e grupos, localizados em qualquer parte do mundo, entram em contato uns com os outros seja de modo simultâneo ou assíncrono.

As redes sociais, no ciberespaço, apesar de fazerem analogia às redes sociais do mundo off-line - estabelecidas pelas conexões comunicacionais e pela formação de agrupamentos 
sociais - não as substituem nem superam as tradicionais formas de associação humana, mas oferecem outras formas de se conectar e aprender. Dessa conexão surgem conhecimentos construídos à múltiplas mãos (LÉVY, 1999, VIEIRA, 2016).

O conhecimento se espalha pela rede de maneira colaborativa, gerados por meio da inteligência coletiva. As pessoas estão ativamente engajadas, pois almejam aprender algo de seu interesse, que seja significativo (SCAICO E QUEIROZ, 2013, p. 891). Desse modo, o processo de aprendizagem se inicia pela interação com aquilo que nos interessa, ou que nos afeta no sentido das emoções.

Consideramos a aprendizagem um processo sistêmico e dinâmico que envolve a complexa conexão entre processos internos e externos. Assim como Illeris (2013) entendemos que o conceito de aprendizagem acopla todos os processos que conduzem os seres vivos a mudança, com exceção daquelas provenientes do amadurecimento biológico ou do envelhecimento. Sua finalidade é expandir a vida, construindo conhecimentos e desenvolvendo potencialidades.

O procedimento para elaboração do conhecimento sofre influência de diferentes dimensões, a citar: as emoções, a cognição, as relações sociais, a estrutura biológica, o contexto e a cultura. Nas Redes a construção do conhecimento ocorre pelo coletivo e torna-se, do ponto de vista do acesso às informações, acessível. Assim, dentro do universo digital, o processo de aprendizagem encontra-se cada vez mais conectado.

Concebemos que as redes sociais digitais são prolongamentos da vida humana e à medida que as pessoas as utilizam, produzem conteúdo, criam e recriam novos modos de interação, compõem maneiras de ser, de estar e de produzir que acabam por influenciar o mundo atual e consequentemente influenciam de volta o universo virtual como em um movimento constante.

Nesse contexto de socialização de informações, debates e contatos sociais a rede social Facebook tem se destacado na preferência dos usuários na Rede. Dados de janeiro de 2019 apontam que mais de 1,5 bilhão de pessoas no mundo acessam o Facebook diariamente (FACEBOOK, 2019). Entre a faixa etária com maior número de acesso estão os adolescentes e jovens. Seguindo a tendência mundial, no Brasil, o Facebook também é uma das redes sociais mais acessadas no país.

Consideramos que a elevada popularidade de uma rede social - decorrente da quantidade de usuários ativos - pode estar relacionada à convergência tecnológica das mídias. A convergência atrai a atenção dos usuários por oferecer no mesmo lugar recursos de diferentes 
mídias ao mesmo tempo em que são de fácil manuseio, o que permite ao usuário interagir, se divertir e aprender.

Como explica Recuero, Bastos e Zago (2015, p. 30/31) os sites de redes sociais ao adicionarem às suas funções habituais aplicabilidades de outras mídias - como: compartilhamento de fotos e de informações, produção e edição de vídeos e bate-papo (chat) com chamada de áudio e vídeo - tornam esses espaços um convite à interação, ao engajamento e à produção de conteúdo pelos usuários.

A produção de conteúdo está diretamente relacionada a processos de aprendizagem. Envolve competências e habilidades como a observação, a disponibilidade para pesquisar e aprender, a motivação, a editoração e o uso da criatividade, para que aquilo que está sendo produzido não seja "mais do mesmo". É possível desenvolver habilidades navegando por links na Internet e consultando diferentes materiais.

Assmann (2005, p.29) assevera que, por meio das redes digitais, desponta-se uma metamorfose do aprender e aprimora-se o potencial cognitivo humano, pelo oferecimento de modos de conhecer até então inexistentes. Conhecimentos que antes estavam restritos à educação formal, nas escolas e nas universidades, agora se espalham de maneira informal pela Rede.

Uma vez que os nós estão conectados pelas inteligências coletivas, gerando debates e aprendizagens em várias áreas do saber, contribuem para construir conhecimento em uma estruturação diferente da educação formal institucionalizada. Através da internet, seja de modo pago ou gratuito, os próprios usuários oferecem cursos, tiram dúvidas, dão dicas e exemplos de estratégias sobre os mais variados assuntos.

Devido a dinamicidade de interações e modos de aprender que ocorre no interior dos sites de redes sociais esses espaços oferecem oportunidades de estudos sobre as relações humanas, práticas culturais da sociedade e consequentemente práticas educativas formais e informais. Configuram-se, pois, como espaços de relevante interesse para pesquisas em Educação.

Definimos como objeto de estudo desta pesquisa as interações nos sites de redes sociais, porque entendemos que essas redes sociais - através da conexão entre pessoas e 'pessoas e máquinas' - estão relacionadas a processos de aprendizagem e elaboração de conhecimento. Buscamos analisar como as diferentes formas de interações ocorridas nos sites de redes sociais estão relacionadas a aprendizagens.

Nesta pesquisa quando falamos de aprendizagem consideramos o termo em seu sentido plural tendo em vista que envolve processo sistêmico sob influência de elementos internos e 
externos. Ademais, entendemos por interação todas as opções disponibilizadas pelos sites de rede social para que o usuário possa conectar-se com outros nós dentro da rede, sejam elas: postagens, reações, compartilhamentos e comentários.

Para este estudo tivemos como vertente de pesquisa os ECE no âmbito do universo digital. Esse campo tem investigado práticas culturais e suas relações educacionais e sociais que vem provocando mudanças significativas no âmbito da sociedade e das instituições educativas formalizadas ou não.

\section{MÉTODO}

Demos início ao procedimento de coleta de dados pela identificação das páginas e postagens na rede social Facebook. Escolhemos como parâmetro páginas brasileiras com o maior número de seguidores e que possuíam postagens atualizadas no ano de 2018. Delimitamos esse período para que pudéssemos coletar dados dos meses de janeiro a junho do referido ano.

A pesquisa pelas páginas foi realizada por meio da opção 'pesquisa' do Facebook utilizando como palavra-chave o nome dos temas dos ECE: 'Cultura Digital', 'Gênero' e 'Inclusão'. Selecionamos um total de seis páginas, duas por tema, sendo elas: 'Mundo Nativo Digital'; 'Casa da Cultura Digital Porto Alegre'; 'É pra falar de gênero, SIM'; 'Grupo de estudos de gênero e sexualidade'; 'A inclusão é direito de todos e Projeto conviver inclusão'.

A partir dessas páginas do Facebook selecionamos as postagens. Para isso sorteamos uma postagem por página, o que resultou em um total de seis postagens sendo duas por tema. Após identificação das páginas e postagens realizamos a análise estatística, o mapeamento das redes de interação e análise dos comentários, que apresentaremos no tópico seguinte: 'resultados'.

Devido à complexidade de informações que na Rede se apresentam de maneira intercruzada para análise dos resultados aplicamos o método ‘Análise de Redes Sociais' (ARS) cujo foco de estudo é o dado relacional (RECUERO, BASTOS e ZAGO, 2015). Este método utiliza softwares para coletar e gerar seus resultados permitindo a visualização de grafos da rede e o estudo a partir de diferentes métricas (medidas).

No caso desta pesquisa com o Facebook utilizamos os softwares NetVizz e NodeXL Pro que, mesmo com limitações impostas pela rede social a partir de 2017, coletaram informações diretamente do Graph API. A Interface de Programação de Aplicativos (API) é um conjunto de 
INOVAÇÃo

funções disponibilizadas pelo programa como a principal forma de extrair e inserir dados na plataforma do Facebook (FACEBOOOK, 2018, s/p).

Para este trabalho utilizamos as versões 1.45 e 1.6 da ferramenta NetVizz. Esse recurso foi desenvolvido em 2009 pelo pesquisador Bernhard Rieder e tem como finalidade "extrair dados de diferentes seções da plataforma do Facebook - em determinados grupos e páginas para fins de pesquisa. As saídas dos arquivos podem ser facilmente analisadas no software padrão" (NETVIZZ, 2018, s/p). Os resultados são liberados em forma de tabelas.

O segundo software utilizado nesta pesquisa foi o NodeXL Pro, desenvolvido pelo grupo do pesquisador Marc Smith. Essa ferramenta é uma das mais executadas para a descoberta de redes, funciona por meio de um plugin para o Programa Microsoft Excel. Executamos o NodeXL Pro em sua versão 1.0.1.407, adquirido por meio de licença de usuário estudantil.

Para visualizar os grafos utilizamos o algoritmo Fruchterman-Reingold, que distribui os nós de forma semelhante no espaço, uma vez que se baseia na força de aproximação e repulsão dos nós (GAMA, BARROS e FERNANDES, 2018; RECUERO, BASTOS e ZAGO, 2015). Também trabalhamos com a especificação direcional dos laços ( $\square$ ), já que os vértices se ligam uns aos outros por meio dos comentários direcionados à postagem (nó central).

Utilizamos também a estratégia de ‘análise do conteúdo' para investigar os comentários dos usuários nas postagens. A análise de conteúdo é um conjunto de técnicas de análise de comunicações que tem como função enriquecer a leitura dos dados coletados (MOZZATO e GRZYBOVSKI, 2011, p.734). Essa técnica de análise dos dados envolve três fases: pré-análise, exploração do material e tratamento dos resultados (BARDIN, 1977).

Nesta pesquisa, a fase 1 (pré-análise) envolveu a transformação do material coletado em um conjunto de textos organizado em arquivo único (SALVIATI, 2017, p.10) com 25 páginas (Corpus). A fase 2 (exploração do material) consistiu na codificação dos dados em unidades de registro (significação), estatísticas textuais, classificação e demais métricas. Já a fase 3 (tratamento dos resultados) foi direcionada a interpretação dos resultados gerados.

Por se tratar de um significativo banco de dados gerenciamos o Software Iramuteq em na versão v 0.7 Alpha 2 e R versão 3.4.0. A função do software foi classificar e categorizar os dados do Corpus. Os resultados obtidos foram interpretados à luz das categorias de análise dos Estudos Culturais em Educação, tendo em vista os processos de interação e aprendizagem. 


\section{RESULTADOS}

Para facilitar a compreensão dos resultados dividimos este item em três partes: 3.1 Dados estatísticos sobre as interações nas postagens do Facebook; 3.2 Análise de conteúdo dos comentários no Facebook; e 3.3 Mapeamento e métricas das redes de interação. Os resultados serão apresentados nos itens a seguir e discutidos de maneira simultânea a partir da fundamentação teórica proposta.

As páginas com postagens e conteúdo analisados foram: 'Mundo Nativo Digital'; 'Casa da Cultura Digital Porto Alegre'; 'É pra falar de gênero, SIM'; 'Grupo de estudos de gênero e sexualidade'; 'A inclusão é direito de todos e Projeto conviver inclusão'.

\subsection{DADOS ESTATÍSTICOS}

Os dados estatísticos foram analisados com base em três pontos: reações (curti, amei, haha, uau, triste e grr); comentários e compartilhamentos a respeito das postagens (conforme Gráfico 1).

Gráfico 1 - Dados referentes às interações no Facebook.

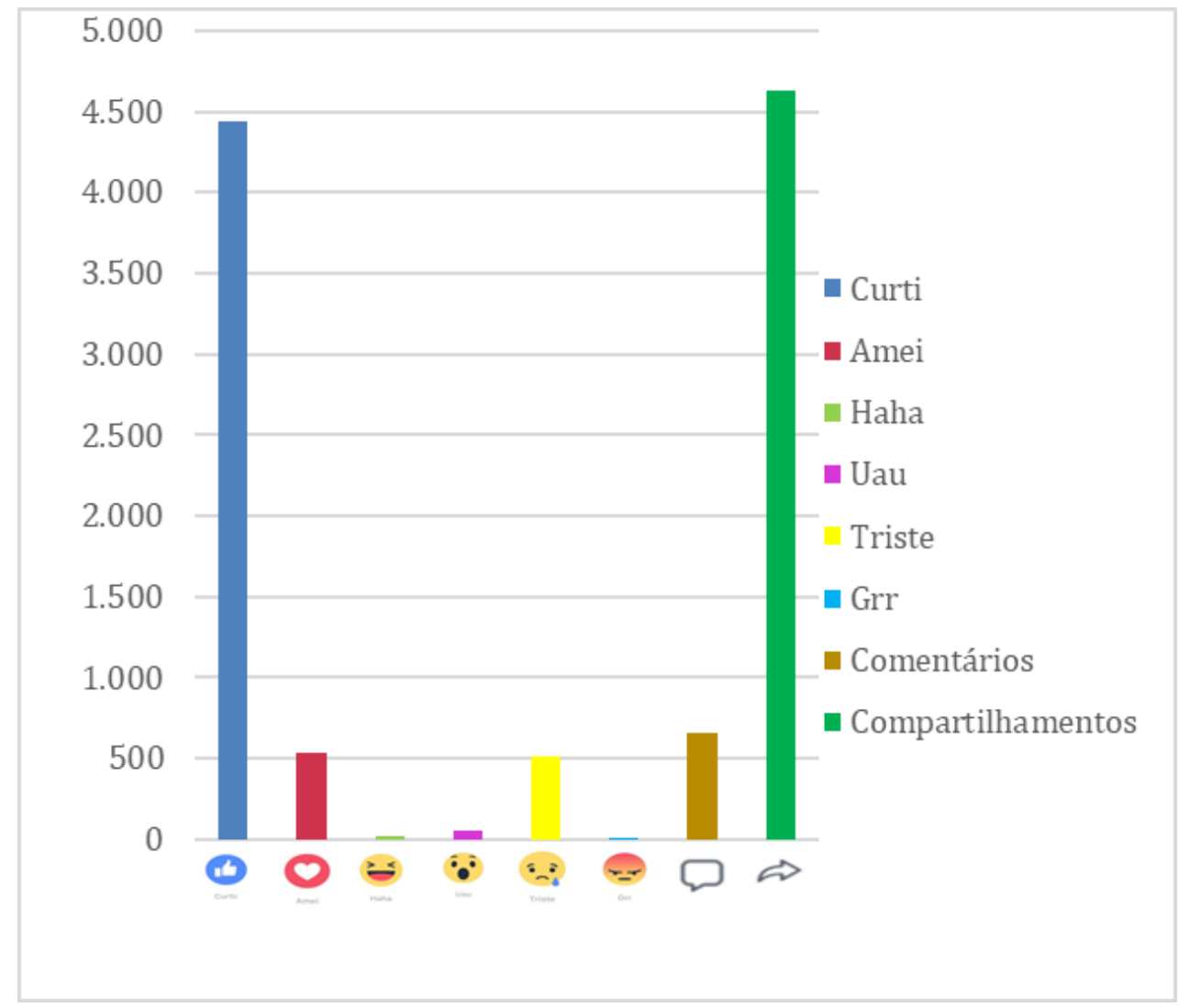

Fonte: Dados da pesquisa gerados no software NetVizz 


\section{ARTIGO}

INOVAÇÃo

De acordo com o Gráfico 1 de todas as formas de interação analisadas o compartilhamento foi a que obteve maior pontuação, sendo um total de 4.629 compartilhamentos. O resultado das demais interações seguem na seguinte ordem de quantidades: curtidas $=4.432$; comentários $=653$; amei $=540 ;$ triste $=507 ;$ uau $=54 ;$ haha $=$ 19 e Grr $=7$.

$\mathrm{O}$ ato de compartilhar simboliza a ação de partilhar ou dividir com alguém uma informação, onde outras pessoas daquela rede de amigos podem ter acesso àquele material. Essa ação amplia a rede de aprendizagens que poderá ser formada a partir da postagem. Entendemos que neste ato de 'com + partilhar' encontra-se implícito um processo de identificação e de aprendizagem coletiva.

Quando compartilho um post é um sinal de que houve uma identificação com seu conteúdo, depois percebo que outros na minha rede também poderiam se interessar pela informação, assim poderei ajuda-los oferecendo elementos para que essas pessoas gerem, consolidem ou revisem seus conhecimentos. O procedimento de compartilhar é um potencial convite à novas interações, pela divulgação da informação e elaboração de conhecimento.

Ademais, podemos encontrar nas legendas (comentário que precede o objeto compartilhado) o resultado de processos de aprendizagem. Nas legendas visualizamos comentários que representam as impressões sobre o material o que indica que foram ativados elementos do processo cognitivo como o pensamento e a linguagem. Para nós essas impressões são produtos de uma engenharia cognitiva que ocorre no interior do sujeito devido as suas relações exteriores e vice-versa da qual resulta o conhecimento.

Levando em consideração o número de compartilhamentos as redes sociais tornam-se ambientes de aprendizagens coletivas, em que o acesso à informação se propaga com muito mais rapidez. Essa facilidade de acesso a informação e conhecimento carrega oportunidades singulares para os participantes fazerem novas descobertas desconectadas dos espaços formais de educação (BRENNAND e BRENNAND, 2010, 2013).

Assim como Paiva (2013, p. 41) compreendemos que as redes "geram processos coletivos de cognição, identificação, convergência e participação". Visualizamos as redes sociais como um espaço onde se dividem saberes, que se expande a cada nova interação e cujo currículo é ilimitado e indefinido, uma vez que os integrantes constroem e trilham seus caminhos a partir de seu ponto de interesse e identificação.

Identificamos que entre os resultados obtidos a segunda forma de interação utilizada pelas pessoas que utilizam as redes sociais foi a reação do tipo like. As reações - curti, amei, haha, uau, triste e grr - representam formas de afeto/sentimentos. O Facebook disponibilizou

P2P \& INOVAÇÃO, Rio de Janeiro, v. 7, n. 1, p. 88-106, set. 2020/fev. 2021. 
esses ícones para que os usuários expressem suas emoções sobre aquilo que aprenderam ou captaram da postagem.

Segundo Illeris (2013, p. 27) o processo de aprendizagem é constituído por elementos cognitivos, vivenciais e afetivos. Este último trata da dimensão da sensibilidade, da emoção, da escuta do outro e das demais expressões afetivas. No Facebook eles estão representados por meio de ícones (símbolos) que podem ser observados através do Gráfico 1. Dentre as reações analisadas o curtir foi a reação com o maior total, chegando a totalizar 4.432 curtidas.

As curtidas, ou o ato de curtir ou dar likes, representa a ação de apoiar a postagem ou de achar interessante o conteúdo da publicação. Seu ícone traz a mão fechada com o polegar voltado para cima que retrata o símbolo de legal, tradicionalmente conhecido. De todas as reações o like foi a primeira reação disponibilizada pelo Facebook. As demais foram incluídas a partir de 2016 após estudos e pesquisas relacionadas, sendo recebidas pelos usuários com sucesso.

Inclusive, o acréscimo de novas reações está relacionado a situações do contexto sociocultural. Em 2020, por exemplo, durante a pandemia de coronavírus o Facebook lançou a reação 'força', cujo ícone é um emoticon de carinha abraçando um coração vermelho. A reação é uma forma de demonstrar apoio a todas as postagens relacionadas a doença, mas como seu uso é construído pela interação social, já houve uma adaptação para a utilização em outras situações.

Percebemos que as vivências e os afetos são elementos importantes do processo de aprendizagem, e as redes sociais já os inclui como opção de interação. Assim como as reações os comentários também servem de fonte de avaliação sobre o conteúdo postado. Quando os participantes interagem comentando ou reagindo um post exprimem sua opinião que é fruto de aprendizagens adquiridas depois de ler ou de visualizar a postagem.

No que se refere aos comentários, as postagens analisadas receberam um total de 653 comentários. A ação de comentar uma postagem representa indiretamente um convite ao diálogo, pois permite a outras pessoas responderem ao comentário e iniciar uma conversação. A conversação, enquanto pilar da interação humana, envolve interpretação, negociação, linguagens, trocas sociais e culturais (RECUERO, 2014, p.31).

De acordo com Kietzmann et al (2011) o conteúdo das conversações inclui formas de expressar o pensamento e as afetividades. Nas redes sociais digitais os comentários das páginas são de livre acesso e oferecem oportunidades de reflexão e conhecimento sobre o conteúdo postado. Os usuários acessam os comentários das postagens para ver opiniões, dicas ou acompanhar de modo silencioso as discussões. 
Ao comparar os três tipos de interação - compartilhamentos, reações e comentários percebemos que, na rede, há uma tendência para a expressão dos usuários por meio de símbolos. Os símbolos do qual nos referimos são os emoticons, que consistem em imagens que representam sentimentos, expressões faciais e muitas vezes substituem as palavras dentro dos comentários.

Essa constatação nos remete a proposta de Lévy (1998) sobre as ideografias dinâmicas, que seriam escritas em movimento, atreladas aos sistemas computacionais, dotadas de sentidos e significados que poderão representar, por exemplo, frases inteiras. De acordo com Lévy (1998), em um futuro próximo, esse tipo de escrita viria a substituir as tradicionais escritas estáticas, como o alfabeto.

Contudo, não defendemos a substituição de uma forma de comunicação por outra, mas compreendemos que há uma mudança na forma de comunicação e expressão a partir das redes sociais digitais que precisa ser considerada e estudada. Essa nova maneira de comunicar é decorrente da cultura da convergência (JENKINS, 2009) e da participação dos sujeitos frente as novas formas de interação humana.

Essas mudanças estão presentes nas redes sociais a partir da utilização das reações 'curti', 'uau', 'amei', 'triste', 'grr' e 'haha' oferecidas pelo Facebook. Essas reações podem ser o início das futuras ideografias dinâmicas de Lévy (1998), pois além de possuírem movimento, também apresentam significados que substituem frases inteiras, cujo sentido pode ser (re) construídos pelos sujeitos em seu processo de interação.

Os símbolos também foram encontrados no conteúdo dos comentários. No item a seguir apresentamos com mais detalhes o resultado desta análise.

\subsection{ANÁLISE DO CONTEÚDO}

Identificamos nos comentários a presença de símbolos, imagens, emoticons, palavras isoladas e pequenos textos, que foram transformados em Corpus. A Figura 1 apresenta exemplos de comentários dos usuários em uma das postagens analisadas.

Iniciamos a análise de conteúdo dos comentários pela frequência de palavras, para isso utilizamos o Diagrama de Zipf (SALVIATI, 2017, p.11). Esse modelo de análise, disponibilizado pelo software Iramuteq, aponta que a maior frequência no Corpus analisado foi o dos nomes de pessoas, ou seja, os usuários mencionavam o nome de outros usuários nos comentários das postagens. Citar o nome de alguém nos comentários foi o aspecto mais frequente que apareceu nos comentários. 


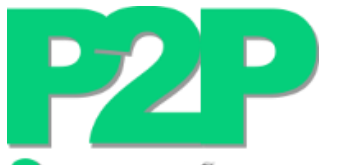

ARTIGO

INOVAÇÃo

Figura 1 - Comentários no Facebook.

\section{Cintia flus Fabi 1 olha que interessante \\ Curtir - Responder - 25 sem}

Fabi manm. Olhaaa... Ja vou baikar... Obrigadinha!

Curtir - Responder - 25 sem

\section{Isadora Cum Debora Escanoela}

Curtir-Responder - 25 sem

Debora la isadora OBRIGADA por me marcartimin Otha isso, Aviane as!

Curtir-Responder - 25 sem

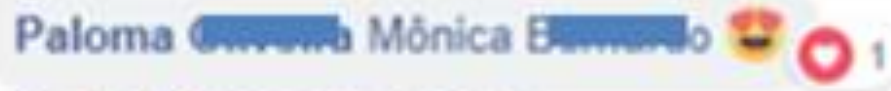 \\ Curtir - Responder - 25 sem}

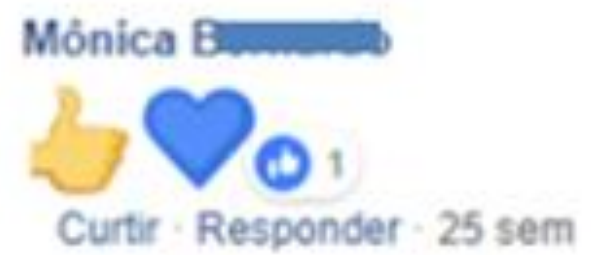

Fonte: Facebook - online.

No Facebook, o ato de um usuário mencionar outro representa um convite para que a pessoa veja a postagem e possa interagir. Quando for mencionada ou "marcada" em um post, a pessoa mencionada receberá uma notificação, que é um sinal de que alguém solicita sua atenção para ver a postagem, e decidirá se deseja ignorar, comentar, reagir ou até mesmo compartilhar a informação postada.

Nas postagens analisadas cerca de 290 pessoas foram mencionadas por outros usuários para visualizar a postagem e se for o caso interagir. Deste total, aproximadamente $81 \%$ das pessoas mencionou o nome de outro usuário de sua rede de amigos, $14 \%$ mencionaram de duas a três pessoas, enquanto que $4 \%$ dos comentários traziam o nome de quatro a cinco pessoas.

Entendemos que ao mencionar o nome de uma pessoa nos comentários os usuários compartilham com ela conteúdos, convidam-na a interagir a partir daquilo que os interessou. 
Para nós essas marcações representam uma inovação nas formas de interagir dos sujeitos no ciberespaço. São frutos de produções culturais decorrentes de interações e aprendizagens significativas, que permitem as pessoas criar novos modos de partilha.

Contudo, a divulgação do conteúdo, por meio da menção de amigos nos comentários, não garante que, quando o nome de uma pessoa for citado, haverá uma conversação. Mas pelo menos é uma oportunidade a mais para iniciar novas interações e aprendizagem. Conforme aponta Illeris (2013, p. 19), a "dimensão da interação propicia os impulsos que dão início ao processo de aprendizagem" e diz respeito às relações de sociabilidade. $\mathrm{O}$ ato de mencionar o outro traz em potencial esta dimensão que poderá iniciar novos saberes.

Ademais, identificamos que os usuários mencionavam o nome das pessoas sem fazer outros comentários e obtinham como resposta apenas uma reação: likes, uau, haha, amei e em poucos casos obtinham algum tipo de resposta comentada como mostra a Figura 1. Nos comentários e nas respostas aparecem emoticons (carinhas, corações, mãos) que se misturam a palavras e a frases para completar seu sentido.

No caso, mostrado na Figura 1, o símbolo de legal e o coração azul substituem por completo uma palavra ou frase, essa simbologia carrega o sentido de aprovação e agradecimento do usuário tanto pela citação de seu nome, como pelo conteúdo compartilhado. Este contexto interacional mais uma vez remete as ideografias dinâmicas apresentadas por Lévy (1998).

Em complemento a análise do conteúdo aplicamos o método de Reinert para identificar quais ideias gerais o Corpus apresenta (SALVIATI, 2017, p.46). Os resultados sinalizam que as pessoas através dos comentários demostram interesse pela postagem e seu tema, quando, por exemplo, manifestam apoio e/ou mencionam outras pessoas de sua rede de amigos.

Os resultados apontaram também que de maneira geral as postagens agradam os usuários que as visualizam como recurso pertinente de informação. Comentários como: “Bem didático. Vou compartilhar. Obrigada!" e "Muito obrigada pelos esclarecimentos" são exemplos de que as postagens analisadas foram avaliadas de maneira positiva pelas pessoas que interagiram através dos comentários, o que corrobora com resultados do número de curtidas e compartilhamentos apresentados no item anterior.

$\mathrm{O}$ ato de compartilhar informações além de ser um meio de divulgar informações também envolve questões relacionadas a identidades e subjetividades, representação de papeis sociais. No comentário: "Bárbara... Lembrei de vc e seu bom gosto por livros", ao mencionar o nome de alguém é porque algo na postagem me chamou a atenção, e desejo compartilhar porque poderá ser de interesse do outro.

P2P \& INOVAÇÃO, Rio de Janeiro, v. 7, n. 1, p. 88-106, set. 2020/fev. 2021. 
Os discursos e os atos contêm signos e significantes e são formas de comunicar aprendizagens adquiridas por meio de trocas sociais (BORDERIE, PATY e SEMBEL, 2007). Neste sentido, identificamos entre o conteúdo analisado comentários que manifestava opiniões dos usuários em relação a postagem, inclusive fazendo uso de conhecimento ou referências cientificas durante a argumentação.

Os sites de rede social são espaços de debates e conflitos, que buscam através dos recursos tecnológicos e convergente alcançar o engajamento dos usuários. As interações são registros de aprendizagem como também formas de expressar o aprendido, seja por meio de ícones (reações), por compartilhamentos ou pelo uso de palavra escrita, como é o caso dos comentários.

Compõem um ambiente de liberdade no qual as pessoas podem expor suas opiniões, seus pensamentos e sentimentos. As interações decorrentes do contato com a postagem formam redes que se ampliam a cada nova interação, apresentamos no item a seguir o mapeamento das redes obtidas a partir dos comentários dos usuários as postagens.

\subsection{MAPAS E MÉTRICAS DE REDE}

Para o mapeamento das redes de interações a partir dos comentários utilizamos o NodeXL Pro e geramos grafos individuais a partir de cada postagem (Cf. Figura 2). Nos grafos cada ponto preto representa um usuário que interagiu comentando a postagem e as linhas (arestas) representam os comentários (linhas na cor cinzas) e as respostas aos comentários (na cor azul).

De acordo com a Figura 2 cada grafo está conectado a um nó central, que é o post. Essa informação pé comprovada pela métrica 'componente conectado' que é um conjunto de nós inteiramente conectados (RECUERO, 2017, p.24), o que significa dizer que os comentários dos usuários estão ligados ao post investigado, como esperado, e que a conjuntura de aprendizagens se encontra conectada ao mesmo ponto de informação: a postagem.

Recuero (2017, p. 19) explica que o posicionamento do nó, no caso dos grafos direcionados, tem a ver com o indegree (grau de entrada), i.e., com a quantidade de conexões que o nó recebe. Nos casos analisados, o nó que representa cada postagem foi o que mais obteve indegree, o que significa dizer que ele foi o responsável por conectar os demais nós a sua volta. 
Figura 2 - Redes de interação nas páginas do Facebook.
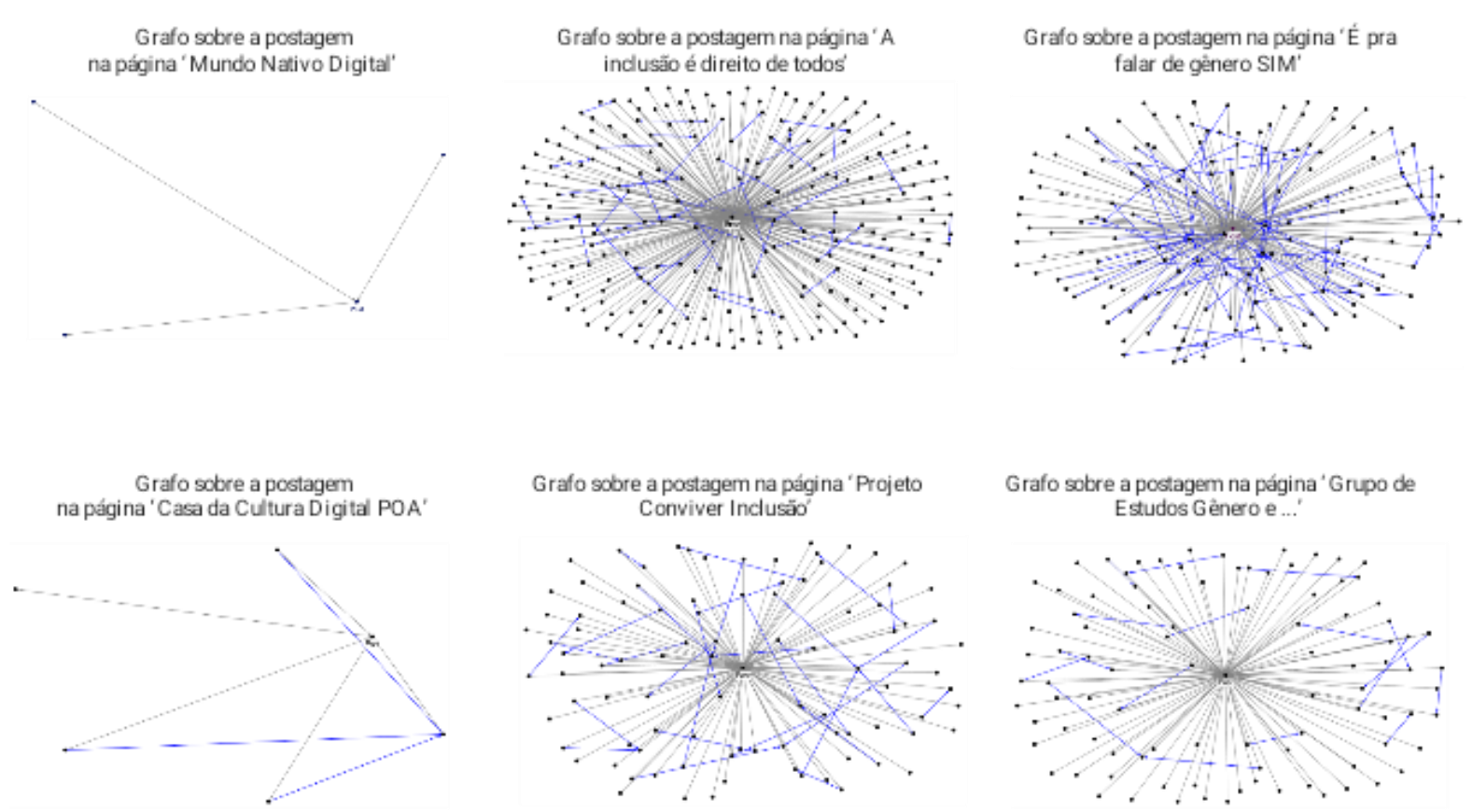

Fonte: Dados da pesquisa.

Na Figura 2 percebemos que os grafos apresentam estruturas diferentes de conexões, isso se justifica pela quantidade de comentários emitidos pelos usuários ao post. Quanto mais comentários e respostas ao post maior será a rede de conexões formada entre os nós. Consequentemente, quanto maior é a conexão dentro de uma rede, maiores são as possibilidades de trocas de informações e conhecimentos.

É interessante observar que, nas redes sociais digitais, apesar do grafo ser uma imagem estática das interações, essa estrutura carrega em si o potencial de se expandir, uma vez que a postagem continua disponível na rede e outras pessoas podem comentar. A Cultura Digital e sua estrutura em rede favorecem os processos de aprendizagem, pois muitas pessoas que estão dentro daquela rede pode ter acesso ao conteúdo divulgado, e construir conhecimento.

Neste sentido, calculamos a medida da distância entre dois nós na rede - distância geodésica - (AQUINO, 2017, p.2041) - que apresentou resultado de, no máximo, duas arestas. Esse resultado indica que dentro da rede o caminho mais longo, nos casos analisados, é aquele que vai do post até uma resposta. Logo, a dinâmica da rede sofre influência dos múltiplos canais de participação dos usuários, como também do sistema computacional (DI FELICE, 2017).

Os sites de redes sociais são, também, espaços de expressão do saber aprendido e de produção de novos conteúdos. Esse fato nos remete ao conceito de 'cooperação cognitiva distribuída' (ASSMANN, 2005) e ao conceito de ecologias comunicativas (DI FELICE, 2017) 
sobre a participação de humanos e não humanos/máquinas no ato conectivo e de construção do saber no universo digital.

Os grafos nos ajudam a visualizar como se estrutura a inteligência coletiva nas redes sociais. Seu comportamento é dinâmico e a cada nova interação, surgem oportunidades de aprender e acessar o conhecimento espalhado na rede (BRENNAND e BRENNAND, 2013). Neste direcionamento, o ato de compartilhar as postagens ou mencionar as pessoas - que é marca dos processos coletivos de aprendizagem (LÉVY, 1999) - carrega em si a possibilidade de ampliar ainda mais as redes de aprendizagens.

Dentro de redes de interação no ciberespaço as aprendizagens ocorrem de maneira espontânea e coletiva, a partir dos conteúdos de interesse dos próprios sujeitos ou de algo que lhes chamou a atenção. O caminho para aprender é trilhado a cada clique que fazemos em um link, pela visualização de fotos e vídeos, pela estruturação da linguagem quando escrevemos uma postagem no status e por meio das diversas formas de interações que fazemos a partir das postagens.

Essas interações são provenientes de uma rede aberta, que pode ser ampliada a cada nova interação dos usuários, o que demarca as características de atemporalidade e aterritorialidade do ciberespaço e da Sociedade em Redes (CASTELLS, 2016). Apesar dos avanços no sentido da 'participação dos sujeitos' Jenkins, Green e Ford (2014, p.197) destacam que nem todos os sujeitos estão de fato inseridos.

É preciso lembrar que há pessoas que não estão incluídas ou estão parcialmente incluídas no universo digital, que apesar de ter acesso aos sites de redes sociais, por exemplo, as utilizam de maneira limitada, sem autonomia e protagonismo. Esse contexto de exclusão/inclusão interfere no processo de aprendizagem e tem relação com o letramento digital e demais procedimentos educacionais oriundos das formações institucionalizadas.

\section{CONSIDERAÇÕES FINAIS}

A proposta deste trabalho foi analisar como as diferentes formas de interações ocorridas nos sites de redes sociais estão relacionadas a aprendizagens. Os resultados indicam que o processo de aprendizagem nos sites de redes sociais começa com as diferentes interações que fazemos nas postagens. Ao clicar em um link, ao visualizar uma imagem ou vídeo e ao escrever no status da rede social estamos ativando processos diretamente relacionados ao ato de aprender. 
Conforme aponta Illeris (2013), a "dimensão da interação propicia os impulsos que dão início ao processo de aprendizagem" (ILLERIS, 2013, p. 19) e diz respeito às relações de sociabilidade. O contato com novas informações, pessoas e tecnologia, a produção de conteúdo, a expressão de pensamentos e percepções proporcionam a ativação de conexões cognitivas, afetivas e vivenciais que são importantes para a dinâmica do aprender.

$\mathrm{O}$ ato de partilhar informações por meio da opção de compartilhamento ou citando o nome dos amigos na rede favorece o circuito de aprendizagens, pois envolve uma das características da Cultura Digital que é a aprendizagem coletiva. De acordo com Brennand e Brennand (2013) o currículo é construído a múltiplas mãos, por isso entendemos que o ato de dividir informações e conhecimento com as pessoas representa essa ação coletiva do aprender.

$\mathrm{Na}$ rede as pessoas utilizam os recursos tecnológicos disponíveis de maneira livre e espontânea. Durante seu percurso de interações nas redes sociais as pessoas entram em contato com novas informações e constroem seus conhecimentos sem que, necessariamente, tivesse definido um planejamento ou objetivos específicos. Nas redes o ato de aprender está disponível a cada click ou interação.

Pela experiência que adquirem as pessoas ajudam umas às outras com dicas e materiais gratuitos sobre diversos temas e assuntos, compondo aquilo que Lévy (2017; 1999, 2010) chamou de inteligência coletiva. Quanto mais informações os usuários divulgam na rede e quanto mais conexões estabelecem maiores são as possibilidades de ampliar as redes de aprendizagens.

Para ampliar a rede de aprendizagens, consideramos pertinente a interação entre humanos e não humanos, pois através das interfaces de fácil acesso, auxiliam a impulsionar o saber. Esse tipo de interação é resultado de processos de aprendizagem que transformam os próprios indivíduos e seu meio. Por isso, concordamos com Di Felice (2017) quando afirma que a tecnologia digital medeia as conexões fazendo parte desse ecossistema cognitivo.

Ao analisar o mapeamento das redes de aprendizagem e interação identificamos que os sites de redes sociais são como teias de infinitas possibilidades para o aprender. Esses ambientes carregam em potencial diferentes oportunidades de conexão e troca de informações que se expande a cada nova interação com ajuda dos sujeitos e das máquinas ao utilizar as tecnologias digitais.

O estudo mostrou que a utilização de símbolos ideográficos, como as reações, são características dos processos de aprendizagem no ciberespaço, pois são formas de expressar elementos cognitivos, afetivos e vivenciais de maneira inovadora. Os símbolos gráficos se misturam aos tradicionais símbolos alfabéticos, e em alguns casos os substituem totalmente, 


\section{ARTIGO}

- INOVAÇÃo

demarcando novas formas de comunicação, a exemplo das ideografias dinâmicas de Lévy (1998).

Os resultados demonstram que as diferentes formas de interação nos sites de redes sociais estão relacionadas a aprendizagens quando esses sites geram engajamento dos usuários e partem daquilo que é interessante aos sujeitos. O compartilhamento de informação amplia, consolida ou instiga novos processos de aprendizagens, iniciando novos ciclos dentro do processo cognitivo do ponto de vista individual e coletivo.

Desse modo, quando os sites de rede social oferecem ferramentas de interação de fácil acesso e utilização, disponibilizam estratégias para produção de conteúdo e promoção do diálogo geram também contextos onde os sujeitos sentem-se participantes do processo de elaboração do conhecimento, pois (re) criam cultura e se tornam, assim, protagonistas na construção coletiva do saber. 


\section{REFERÊNCIAS}

AQUINO, Israel da Silva. Análise de redes de compadrio na freguesia de Viamão (Século XVIII). In: SANTOS, Amanda Basilio; MACHADO, Juliana Porto; COLVERO, Ronaldo Bernardino. Interdisciplinaridade nas ciências humanas. Caminhos da pesquisa contemporânea. Jaguarão: Editora CLAEC, 2017. 2888 p. ISBN 978-85-93548-05-5 Disponível em: https://goo.gl/XGDx2C. Acesso em: 14 dez. 2019.

ASSMANN. Hugo. A metamorfose do aprender na sociedade do conhecimento. In: ASSMANN, Hugo. Redes digitais e metamorfoses do aprender. Petrópolis: Vozes, 2005. 128 p. ISBN 978-8532631534.

BARDIN, Laurence. Análise de Conteúdo. Lisboa: Edições 70, 1977. 225 p. ISBN 9789724408989.

BORDERIE, René La; PATY, Jacques; SEMBEL, Nicolas. As ciências cognitivas em educação. São Paulo: Edições Loyola, 2007.

BRENNAND, E. G. G.; BRENNAND, Eládio de Góes. Informação interativa e a formação de colégios invisíveis. Informação \& Sociedade (UFPB. Online), v. 23, p. 89-99, 2013.

CASTELLS, Manuel. A sociedade em rede. 17a edição. São Paulo: Paz e Terra, 2016. 632 p. ISBN 9788577530366.

DI FELICE, MASSIMO. Net-ativismo: da ação social para o ato conetivo. 1 ed. São Paulo: Paulus Editora, 2017. 288 p. ISBN 9788534945745

DYSSON, Esther; GILDER, George; KEYWORTH, Jeorge; TOFFLER, Alvin. Ciberespaço e o sonho americano: Uma magna carta para a era do conhecimento. Progress \& Freedom Foundation, 1994. Disponível em: http://www.pff.org/issues-pubs/futureinsights/fi1.2magnac arta.html. Acesso em:13 dez. 2019.

FACEBOOK. Ferramentas para desenvolvedores. Online, 2018. Disponível em: https://developers.facebook.com/tools/. Acesso em: 25 abr. 2018.

FACEBOOK. Marketing. Facebook. Site Facebook, online, 2019. Disponível em: https://www.facebook.com/business/marketing/facebook. Acesso em: 11 mai.2019.

GAMA, Rui; BARROS, Cristina; FERNANDES, Ricardo. Science Policy, R\&D and Knowledge in Portugal: an Application of Social Network Analysis. Journal of the Knowledge Economy v. 9, n. 2, 2018. Disponível em: https://doi.org/10.1007/s13132-0170447-3. Acesso em: 15 jun. 2018.

ILLERIS, Knud. Uma compreensão abrangente sobre a aprendizagem humana. In: ILLERIS, Knud. Teorias contemporâneas da aprendizagem. Porto Alegre: Penso, 2013. 280 p. ISBN 9788565848305.

JENKINS, Henry. Cultura da Convergência. São Paulo: Aleph, 2009. 432 p. ISBN 9788576570844. 
JENKINS, Henry; GREEN, Joshua; FORD Sam. Cultura da Conexão: criando valor e significado por meio da mídia propagável. São Paulo: Aleph, 2014. 408 p. ISBN 9788576571629.

KIETZMANN, J.H.; HERMKENS, K.; MCCARTHY, I.P.; SILVESTRE, B.S. Social media? Get serious! Understanding the functional building blocks of social media. Business Horizons, Vol. 54(3), p. 241-251, 2011.

LÉVY, Pierre. A ideografia dinâmica: rumo a uma imaginação artificial? São Paulo: Edições Loyola, 1998. 232 p. ISBN 978-8515016709.

LÉVY. Pierre. A inteligência coletiva: Por uma antropologia do ciberespaço. São Paulo: Edições Loyola, 1999.

LÉVY, Pierre. Cibercultura. São Paulo: Editora 34, 2010. 272p. ISBN 978-8573261264.

LÉVY, Pierre. A esfera pública do século XXI. In: DI FELICE. Massimo., PEREIRA, Eliete. e ROZA, Erick. Net-ativismo: Redes digitais e novas práticas de participação. Campinas: Papirus, 2017. 288 p. ISBN 9788534945745.

MOZZATO, Anelise. Rebelato; GRZYBOVSKI, Denize. Análise de conteúdo como técnica de análise de dados qualitativos no campo da administração: potencial e desafios. RAC. Revista de Administração Contemporânea, v. 15, n. 4, 2011. Disponível em: https://rac.anpad.org.br/index.php/rac/article/view/874. Acesso em: 14 dez. 2019.

NETVIZZ. Aplicativo Netvizz v1.44. (online), 2018. Disponível em: https://apps.facebook.com/netvizz/?ref=br_rs. Acesso em: 23 nov. 2018.

PAIVA, Cláudio C. Hermes no ciberespaço: uma interpretação da comunicação e cultura na era digital. João Pessoa: Editora UFPB, 2013.

RECUERO, Raquel. Introdução à análise de redes sociais online. Salvador: EDUFBA, 2017. (Coleção Cibercultura) ISBN 978-85-232-1669-6.

RECUERO, Raquel; BASTOS, Marco; ZAGO, Gabriela. Análise de redes para mídia social. Porto alegre: Editora Sulina, 2015. 182 p. ISBN 978-8520507339.

RECUERO, Raquel. A conversação em rede: comunicação mediada pelo computador e redes sociais na Internet. Porto Alegre: Sulina, 2014.

SALVIATI, Maria. Elisabeth. Manual do Aplicativo Iramuteq (versão 0.7 Alpha 2 e R Versão 3.2.3). Planaltina, 2017. Disponível em: http://www.iramuteq.org/documentation/fichi ers/manual-do-aplicativo-iramuteq-par-maria-elisabeth-salviati/view. Acesso em: 14 dez. 2019.

SCAICO, Pasqueline Dantas. QUEIROZ, Ruy José Guerra Barretto de. A educação do futuro: uma reflexão sobre aprendizagem na era digital. II Congresso Brasileiro de Informática na Educação (CBIE 2013). XXIV Simpósio Brasileiro de Informática na Educação (SBIE 2013). 2013. P. 889 - 893.

VIEIRA, Kalyne de Souza. Movimento põe no rótulo: Net-ativismo: redes sociais digitais. 2016. Dissertação. (Mestrado em Comunicação) Programa de pós-graduação em Comunicação, Universidade Federal da Paraíba, Joao Pessoa, 2016. 